\title{
Escenario agroalimentario contemporáneo: desafíos y oportunidades de la producción artesanal de alimentos de Magdalena, Sonora
}

\section{Contemporary Agri-Food Scenario: Challenges and Opportunities of Artisanal Food Production in Magdalena, Sonora}

\author{
Cynthia Paola Gallego Gauna* (iD https://orcid.org/0000-0002-3929-9551 \\ María del Carmen Hernández Moreno** (D) https://orcid.org/0000-0002-8439-4232
}

\section{Resumen}

Objetivo: analizar las oportunidades y los desafíos de la producción artesanal de alimentos en Magdalena de Kino, Sonora, en un contexto en el que convergen la hiperindustrialización alimentaria y la multiplicidad de movimientos sociales que construyen alternativas alimentarias más sanas, ecológicas y justas. Metodología: con base en la teoría de los regímenes alimentarios y en el enfoque de sistemas agroalimentarios localizados, se diseñó una estrategia teórico-metodológica para identificar las dinámicas territoriales en torno a esta actividad. La información se completa con las percepciones de los productores, los consumidores y los informantes clave. Resultados: la escasez de materia prima producida localmente y la falta de cohesión social entre las unidades de producción artesanal de alimentos son los desafíos principales. Empero, el apego de dicha industria a la tradición, y la valoración que de ella se hace, inducen a los consumidores a sostener esta actividad en la región. Limitaciones del estudio: la carencia de un censo de unidades de producción artesanal de alimentos no permitió obtener una muestra estadísticamente representativa; sin embargo, ésta sí lo es de su heterogeneidad. Conclusiones: para catapultar este tipo de producción se requiere la atención multisectorial, centrada en la rehabilitación agroecológica de la producción primaria, la acción colectiva de los productores y la creación de una ruta gastronómica. Palabras clave: aproducción artesanal de alimentos; teoría de los regímenes alimentarios; sistemas agroalimentarios localizados; Magdalena de Kino.

Cómo citar: Gallego Gauna, C. P., y Hernández Moreno, M. C. (202I). Escenario agroalimentario contemporáneo: desafíos y oportunidades de la producción artesanal de alimentos de Magdalena, Sonora. región y sociedad, 33, el 382. doi: I0.22 I 98/rys202 I/33/I382

* Autora para correspondencia. Centro de Investigación en Alimentación y Desarrollo, A. C. Carretera Gustavo Enrique Astiazarán Rosas Núm. 46, C. P. 83304, Hermosillo, Sonora, México. Correo electrónico: cynthia.8710@gmail.com

** Centro de Investigación en Alimentación y Desarrollo, A. C., Coordinación de Desarrollo Regional. Carretera Gustavo Enrique Astiazarán Rosas Núm. 46, C. P. 83304, Hermosillo, Sonora, México. Correo electrónico: mar@ciad.mx

Recibido: 18 de agosto de 2020.

Reevaluado: 8 de diciembre de 2020.

Aceptado: 20 de enero de 2021.

Liberado: 8 de febrero de 2021. 


\section{Introducción}

El surgimiento y la evolución del sistema agroalimentario industrializado en el siglo XX trajeron consigo cambios en las dinámicas sociales, culturales, económicas y alimentarias, tendientes a la estandarización, homogenización y estructuración a través de los mercados. Primero los Estados-nación, y después las corporaciones globalizadas, impulsaron dicho paradigma (Friedmann y McMichael, 1989; Hatanaka y Busch, 2008), que desplazó a otras formas de producir alimentos, como las artesanales, cuya lógica de funcionamiento difiere en su totalidad de la maximización de la ganancia, prevaleciente en la industria alimentaria contemporánea (Campbell, 2005; Domínguez-López, Villanueva-Carvajal, Arriaga-Jordán y Espinoza-Ortega, 2011; Hernández y Villaseñor, 2014; Ransom, Bain y Higgins, 2013).

En las postrimerías del siglo XX e inicios del XXI se conjuga una serie de fenómenos disímiles que entrelazan los problemas sanitarios, el cambio climático y el incumplimiento de los objetivos del milenio, entre otros, en cuyo epicentro destaca el modelo agroalimentario hegemónico, llamado también sistema agroalimentario globalizado (SAG) (Calle, Gallar y Candón, 2013; Otero, 2013) o corporativo (McMichael, 2009). En respuesta a este sistema, se están multiplicando alrededor del mundo diversos movimientos sociales que proponen modelos agroalimentarios alternativos, asentados en el consumo reflexivo y en las prácticas agroecológicas que incluyen nuevas formas de intercambio de alimentos, de conocimientos, de relaciones socioalimentarias y socioambientales (Bowen y Mutersbaugh, 2014; Calle, Soler y Vara, 2009; Fonte, 2008; Guzmán-Sevilla, 2017; McMichael, 2014; Sánchez, 2010), en suma, una nueva gobernanza alimentaria (Mount, 2011).

Es en esta coyuntura que se reivindica la producción artesanal de alimentos (PAA), asociada con una oferta más sana y ecológica, que abre un nuevo horizonte de oportunidades para las unidades familiares de producción artesanal de alimentos (UFPAA), después de ocho décadas de rezago. Se considera la PAA una parte importante del movimiento socioalimentario que se basa en valores -la identidad, la preservación o la renovación de las culturas culinarias localizadas - y en el consumo cívico para revertir los estragos del modelo dominante (Avieli y Cotta, 2015; Bessiere, 1998; Bowen, 2011 y 2014; Calle, Soler y Vara, 2009; Domínguez-López et al., 2011; García, 2012; Muchnik, 2006; Viertel, 2013).

Existen diversos estudios sobre producciones artesanales en los que se destaca la importancia que tienen el territorio y los recursos locales para la agregación de valor. Ortega, Vásquez, Flores y Núñez (2017) subrayan el valor que representa el uso de procesos tradicionales, de técnicas ancestrales y la especificidad que confiere a la calidad de los alimentos usar los insumos locales. Por su parte, Aguilar, Sacco y Velleda (2011) aluden a las características del terroir, representadas por el saber hacer de los integrantes de las comunidades donde se elabora el producto, y señalan que el potencial de los atributos territoriales y su aportación al desarrollo se debe a la gestión de proyectos in- 
tegrales que protegen y promueven la PAA, apuntalada por actividades, como las del turismo rural (Muchnik, 2006).

Bajo esta perspectiva teórica, es posible identificar dos movimientos contrapuestos: 1) la evolución del sistema agroalimentario globalizado, corporativo o neoliberal como fuerza dominante y excluyente y 2 ) la revalorización de los alimentos con identidad territorial a través del surgimiento y el refuerzo de las redes de producción-consumo, movimientos alimentarios que en la actualidad van en ascenso (Campbell, 2009; McMichael, 2014).

En ese contexto se ubica el objetivo del estudio: establecer los desafíos y las oportunidades que tiene la PAA de Magdalena de Kino, Sonora, frente a las ya descritas tendencias del actual escenario alimentario. La región de estudio se configuró a partir de las articulaciones definidas para la PAA entre las localidades de los municipios de Magdalena de Kino - Magdalena y San Ignacio- y de Ímuris -Terrenate y La Mesa-, interconectadas desde la época de las misiones (Ruiz, 2020) por un camino real, que hoy prevalece como ruta alterna a la Carretera Federal 15. La zona es productora reconocida de cajeta de membrillo y conservas de frutas artesanales; también como reservorio de tradiciones culturales, religiosas y gastronómicas. En ella se realizan festividades, se ubican monumentos históricos y es la cuna de personajes célebres, atributos que la destacan como centro de atracción turística en la región Sonora-Arizona (Salido, López, Bañuelos, Romo y Wong, 2009).

La investigación es de alcance descriptivo con enfoque mixto y tiene como insumo principal las opiniones de las personas que integran las UFPAA de la región y las de los consumidores, en su mayoría provienen estos últimos de otras localidades. Se utilizaron entrevistas semiestructuradas en las UFPAA para conocer sus experiencias, motivaciones y expectativas sobre la PAA. También se realizó una encuesta para caracterizar las preferencias y la valoración que dan los consumidores a los alimentos artesanales. Esta información se respaldó, amplió, contrastó y complementó mediante entrevistas semiestructuradas a servidores públicos locales cuyas funciones se relacionan con la PAA. Con el mismo propósito se recurrió a la revisión de fuentes secundarias. El análisis y la exposición de los resultados se hicieron con base en las dimensiones del enfoque de los sistemas agroalimentarios localizados (SIAL) y las dinámicas territoriales propuestas por Muchnik (2006). Eso permitió registrar la diversidad de actividades que se articulan con la PAA y fundamentar su potencial como motor de desarrollo local (Vandecandelaere, Arfini, Belleti y Marescotti, 2010).

\section{Desplazamiento y revalorización de la producción artesanal de alimentos. Una lectura a partir de la teoría de los regímenes alimentarios y del enfoque de sistemas agroalimentarios localizados}

Para entender las fuerzas contrapuestas que enmarcan la evolución reciente de la PAA y para visualizar su potencial de contribución al desarrollo local en 
la región de estudio, se utilizaron dos perspectivas de análisis complementarias: la teoría de los regímenes alimentarios (TRA) de Friedmann y McMichael (1989) y McMichael (2009 y 2014) y el enfoque de los sistemas agroalimentarios localizados (SIAL) (Muchnik, 2006). La TRA permite explicar los factores que incidieron en el desplazamiento de la PAA durante el siglo XX y su actual revaloración como expresión de un movimiento global de la sociedad postindustrial que reúne a consumidores críticos y proactivos (Busch y Bain, 2004; Hatanaka y Busch, 2008), así como a productores rurales y artesanales marginados por el SAG.

En principio, la TRA estudia las expresiones estructurales del sistema alimentario en el contexto del desarrollo económico y de la acumulación de capital. Atendiendo las especificidades histórico-políticas, Friedmann y McMichael identifican varios periodos o regímenes alimentarios cuyos inicios se ubican a finales del siglo XIX, en la Revolución Industrial. Con un enfoque regulacionista y geopolítico, los autores señalan de cada periodo (colonial, superavitario-estatal y corporativo-neoliberal) aquellos elementos que caracterizan, dinamizan y promueven la transición de un régimen alimentario a otro. Para los propósitos del presente análisis, basta con enunciar que en este maxiproceso "la producción agrícola se trasformó de ser una actividad artesanal, realizada por una multitud de agentes económicos de pequeña escala, $a$ lo ancho del planeta, a convertirse en una gran industria controlada por unas pocas corporaciones alimentarias de alcance mundial" (Hernández y Villaseñor, 2014, p. 559). La intensificación y la hipertecnificación agroalimentaria, las políticas públicas orientadas a favorecer la gran industria y las exigencias de las regulaciones inherentes sobre todo al régimen corporativo, neoliberal o al SAG, demandaron ascendentes y cuantiosas inversiones que se convirtieron en los mecanismos de exclusión.

Ahora bien, la revalorización de la PAA se gesta en el marco de las tensiones provocadas por dinámicas contrapuestas, consustanciales al sistema agroalimentario globalizado: una agricultura globalizada y centralizada por unas cuantas corporaciones y la orientación al mercado local de la mayoría de los agricultores del mundo. En términos territoriales, esta tensión se da entre las formas de integración global de las regiones productoras y las consumidoras, cada vez más definidas por los alimentos estandarizados (monocultivos e insumos de origen mundial) versus los sistemas alimentarios biorregionales o locales que reducen la distancia entre los productores y los consumidores. En esta dinámica de resistencia es donde tiene lugar la revaloración de la PAA mediante las cocinas apropiadas y las prácticas ecológicas (McMichael, 2014). Fischler y Solana (2010) exponen cómo los efectos de la industrialización científica de los alimentos contribuyen a provocar desconfianza en el modelo alimentario actual, debido a los rasgos antinaturales o sintéticos de los alimentos.

Los alimentos artesanales tienen un anclaje territorial que rebasa lo tangible. Son la expresión de los atributos naturales del territorio, del saber hacer y de la cultura desarrollados por una comunidad, lo que proporciona calidad y originalidad en la cadena de valor del producto (Vandecandelaere et al., 
2010). Eso es lo que ocurre con la producción de cajeta de membrillo (CM) y de conservas de frutas (CF) en la región de Magdalena de Kino, Sonora. Por esa razón se abordó la problemática de manera sistémica, mediante el enfoque de los SIAL como herramienta de análisis.

Un alimento artesanal es la representación de los atributos de un territorio específico. Su tipicidad deviene de ser producido en pequeña escala, con mano de obra familiar. El uso de herramientas mecanizadas es mínimo y en su manufactura hay un alto aprovechamiento de insumos locales (socioculturales y naturales) (Camacho, Cervantes, Cesín y Palacios, 2019). La PAA es herencia cultural, una forma de agregar valor a la producción primaria local, lo que no excluye la innovación (Brunori, Proost y Rand, 2020). Los productos elaborados de manera artesanal no son piezas de museo; por el contrario, se recrean y actualizan constantemente, sin sacrificar los atributos que los diferencian de la producción industrial.

La PAA funciona bajo una lógica distinta de la maximización de la ganancia (Barragán y Ovando, 2019; McMichael, 2009). Si bien como actividad económica tiene un rol significativo en la reproducción de la UFPAA, sus motores también se relacionan con el prestigio social, la tradición y el fuerte enraizamiento comunitario (Hernández y Villaseñor, 2014). Ante la estandarización, la intensificación y el abaratamiento del sistema agroalimentario globalizado (McMichael, 2014), la PAA opone su tipicidad (Villegas y Cervantes, 2011). La sencillez de sus procesos productivos le confiere un carácter social y económico incluyente, y sus fuertes vínculos con los ecosistemas locales la hacen potencialmente agroecológica (Calle, Gallar y Candón, 2013). Estos atributos contribuyen a salvaguardar su valor específico, con dificultad replicable por la producción industrial.

En efecto, los alimentos artesanales expresan un compendio de elementos biofísicos y culturales, de conocimientos y habilidades acumuladas (Camacho et al., 2019) que se vinculan a través de un entramado de actividades diversas, articuladas para producir gustos y sabores basados en el lugar de origen. El terroir, entendido como un espacio configurado por infraestructuras, interacciones sociales, conocimientos, representaciones, códigos y los valores que le dan sentido y estructura (Linck, Barragán y Casabianca, 2006), desempeñan un papel central en la PAA; es más, son interdependientes, ya que los productores relacionan su tipicidad con el terroir y, a su vez, éstos contribuyen a su patrimonialización, es decir, a la activación y el reconocimiento sociocultural y económico de los atributos del territorio.

Estas consideraciones justifican la pertinencia del enfoque de los SIAL como herramienta para analizar las dinámicas territoriales en las que se realiza la PAA. Su visión sistémica permite trascender el análisis sectorial de la producción alimentaria y reconocer su potencial contribución al desarrollo local (Hernández, 2012). En términos teóricos, los SIAL se refieren al acopio agroalimentario fincado en la economía de las proximidades y situado de manera espacial. El ambiente, los insumos y productos, los actores, sus instituciones, su saber hacer, sus comportamientos alimentarios y sus redes de relaciones, se 
combinan en un territorio para producir una forma específica de organización agroalimentaria en una escala espacial dada (Hernández, 2012, p. 68).

La proximidad, que entraña el anclaje territorial de la PAA a través de sus cadenas locales de suministro y de circuitos cortos de comercialización, se convierte en un atributo más al ofrecer el andamiaje adecuado para el flujo de saberes tradicionales - pero también innovadores-, y la recreación nutrida de relaciones cara a cara entre productores y consumidores generan confianza, sentido de identidad y de pertenencia (Hernández y Villaseñor, 2014), a diferencia de los principios abstractos de fe que prevalecen en los productos manufacturados (Bowen y Mutersbaugh, 2014). Así mismo, la proximidad espacial y la sencillez de los procesos productivos artesanales favorecen una mayor participación de los actores locales en las cadenas de valor (Villegas y Cervantes, 2011) de la PAA, lo cual posibilita que sus beneficios económicos permanezcan en el territorio.

En suma, este conjunto de atributos de la PAA perfila su potencial como estrategia de desarrollo, centrada en la mejora de la calidad de vida de los habitantes de las comunidades y en la construcción, reconstrucción y defensa del territorio (Camacho et al., 2019) en términos identitarios, culturales, sociales y agroecológicos, de ahí la importancia de impulsar iniciativas y políticas públicas que resalten los elementos identitarios y los recursos potenciales del territorio (Törey, 2010). Con esta perspectiva del tema, el enfoque de los SIAL es de gran utilidad, porque permite reconocer las articulaciones agroalimentarias que agregan valor a los productos primarios, que les confieren tipicidad y contribuyen a la mejora de los ingresos de las economías familiares, a la creación de empleo en zonas rurales (Fournier y Muchnik, 2012) y a una oferta de alimentos sanos, con identidad territorial, producidos con menor procesamiento e impacto ambiental.

\section{Metodología}

Con base en la TRA, producir alimentos de manera artesanal se concibe como una actividad que, si bien fue desplazada durante el proceso de industrialización agroalimentaria, por considerársela resquicio del pasado, sinónimo de atraso, en la actualidad se ve reivindicada por diversos movimientos socioalimentarios a escala mundial, que la enarbolan -junto a la producción agroecológica y al turismo alternativo, entre otras-como expresiones de resistencia frente al sistema agroalimentario globalizado (McMichael, 2014). Esta consideración permite vislumbrar el presente como un momento oportuno para reactivar la PAA en la región de estudio. Para documentar de modo empírico las dinámicas territoriales que se entretejen en torno a esta actividad (Muchnik, 2006), el enfoque de los SIAL resultó ser una herramienta pertinente porque facilita la identificación de las diversas articulaciones locales entre actividades económicas y las no económicas, incluidos elementos tangibles e intangibles conjugados alrededor de la PAA. 


\section{Diseño metodológico}

Este estudio sobre los desafíos y las oportunidades que representan el escenario agroalimentario contemporáneo para las familias dedicadas a la producción y venta de CM y CF en la región de estudio, se llevó a cabo a partir de las opiniones de los miembros de las UFPAA, complementadas con la valoración que hacen los consumidores de los alimentos artesanales. En el primer caso, éstas se registraron a través de entrevistas semiestructuradas; en el segundo, mediante la aplicación de una encuesta. La valoración institucional de la PAA se obtuvo tras realizar entrevistas semiestructuradas a servidores públicos de Magdalena de Kino, relacionados con la actividad, y se efectuó una investigación documental para reconstruir el contexto histórico de la PAA.

La selección de las UFPAA se hizo con base en la técnica bola de nieve, siguiendo dos criterios de inclusión: a) que operasen en la región de estudio y b) que exhibiesen diversos grados de integración productiva. Con base en la información de Nigh y González (2015) y Turner y Davidson-Hunt (2016), las UFPAA se dividen en las siguientes categorías: altamente integradas, cuando abarcan producción primaria, transformación y venta; medianamente integradas, cuando incluyen transformación y distribución; y no integradas, cuando sólo se dedican a la venta.

Con base en la información proporcionada por los productores, se obtuvo un universo de 26 UFPAA, con diferentes grados de integración. Entre abril y julio de 2019, se realizaron seis entrevistas in situ -dos de cada categoría- y se mantuvo la comunicación vía telefónica y por medio de redes sociales hasta el mes de marzo de 2020. Los puntos abordados fueron: historia familiar y PAA; saber hacer, tradición y procesos; limitaciones y problemas de la PAA; oportunidades y fortalezas de la PAA; relaciones sociales en torno a los alimentos artesanales (AA); e importancia y valoración de la CM y CF de la región.

Debido a la magnitud del universo de los consumidores, el tamaño de la muestra se calculó con base en una fórmula para poblaciones infinitas (Salido, 2018):

$$
\frac{n_{o}=t^{2} p q}{d^{2}}
$$

Donde:

$n_{0}=$ tamaño de la muestra requerida

$t=$ nivel de confianza deseado (1.96)

$p=$ proporción de que el individuo sea encuestado

$q=$ proporción de que el individuo no sea encuestado

$d=$ error de estimación (0.1).

El resultado obtenido fue de 96 individuos; sin embargo, dada la alta afluencia de consumidores cuando se realizó la encuesta, se aplicaron 111 cuestionarios. Ello ocurrió durante las fiestas de San Francisco Javier, santo patrono de Magdalena de Kino, considerada por Ayón (2010, p. 33) la mejor época en el año, debido a la mayor presencia del turismo religioso en la localidad. En esta 
ocasión, las festividades tuvieron lugar del 27 de septiembre al 6 de octubre de 2019. Como criterios de inclusión, se consideraron personas mayores de 18 años, consumidoras de alimentos artesanales producidos en la región, fuesen o no residentes locales. El acopio de la información se realizó en dos plazas aledañas al templo de culto.

El cuestionario tuvo dos secciones: la primera, para conocer las preferencias alimentarias de los consumidores en función de sus perfiles sociodemográficos (Kranjac, Vapa-Tankosić y Knežević, 2017; Verain, Bartels, Dagevos, Sijtsema, Onwezen y Antonides, 2012; Vessia, 2019); la segunda indagó sobre las razones y los lugares de compra de los $\mathrm{AA}$, y su importancia en relación con el consumo que las nuevas generaciones hacen de ellos. También se preguntó sobre su contribución económica, la ampliación del mercado y el desarrollo regional. Se evaluaron 16 reactivos con base en una escala tipo Likert (Bertram, 2008; Matas, 2018) y una pregunta abierta.

Se formularon, además, cuatro guiones dirigidos a los servidores públicos activos o jubilados- cuyas funciones se relacionan con la PAA: 1) al director de Desarrollo Económico y Turismo Municipal, para corroborar y ampliar la información obtenida de las UFPAA; 2) a dos empleados (uno activo y otro jubilado) de la Secretaría de Agricultura y Desarrollo Rural (SADER), para indagar sobre la evolución de la producción de frutales en la región; 3) al responsable del Departamento de Regulación Sanitaria Municipal, para conocer los requerimientos aplicados a la PAA; y 4) a un técnico de campo, retirado de lo que hoy es SADER, para reconstruir la época de auge de la producción de frutales.

La captura y el primer análisis de la información se hicieron con el programa Excel de Microsoft Office. Para el grupo de las UFPAA, los datos se sistematizaron en una matriz que permitió desagregarlos y realizar los cruces necesarios para su interpretación. Con base en la encuesta, se estructuró una matriz de respuestas agrupadas por rangos de edad para su caracterización. La referencia a los ingresos de los participantes tuvo como base la Encuesta Nacional de Ingresos y Gastos de los Hogares (Instituto Nacional de Estadística y Geografía [INEGI], 2018). El análisis partió del cruce de edad con el resto de los indicadores sociodemográficos y finalizó con las percepciones sobre la valoración de los AA. Para los servidores públicos se utilizaron matrices individuales que luego fueron contrastadas entre sí. La investigación documental sobre la región de estudio incluyó reseñas históricas, censos de población, censos económico-productivos y datos técnicos. El siguiente tratamiento de la investigación se realizó con base en tres niveles de análisis del enfoque de los SIAL: UFPAA (productores), el saber hacer y los consumidores. La exposición de los resultados utilizó como eje estructurante una adaptación de las dimensiones territoriales propuestas por Muchnik (2006).

\section{Dinámicas territoriales de la PAA en Magdalena de Kino, Sonora}

Hablar de PAA es hacer referencia a la CM y a las CF, resultantes de la conjugación de diversos elementos que se entretejen a partir de tres elementos prin- 
cipales: productores, saber hacer y consumidores. De ellos se deriva una red de recursos tangibles e intangibles y de actores implicados, necesarios para agregar valor al alimento artesanal. Dicha red expresa de forma territorial la interacción de la PAA con múltiples sectores económicos y elementos identitarios, lo cual le confiere a ésta atributos que patrimonializan el territorio (Espeitx, 2008), como lo señala la figura 1.

Figura 1. Dinámicas territoriales de la PAA en Magdalena de Kino, Sonora

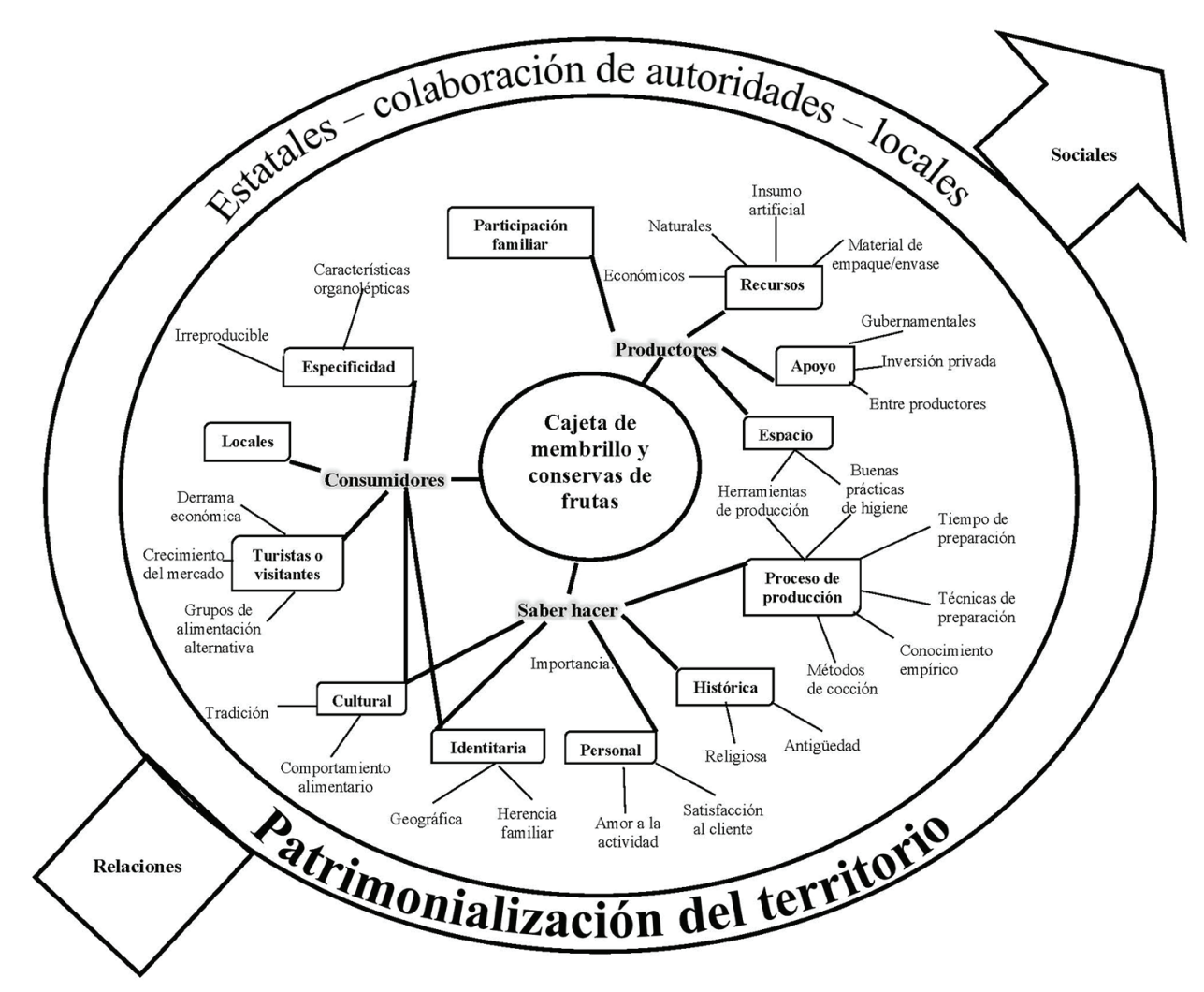

Fuente: elaboración propia.

Dimensión espacial: el territorio

El territorio adquiere un protagonismo determinante en la configuración de los SIAL, de ahí la necesidad de destacar que se trata de una región constituida desde el siglo XVII, que permanece vigente gracias al mantenimiento de un antiguo camino real, a través del cual se realiza buena parte de las interaccio- 


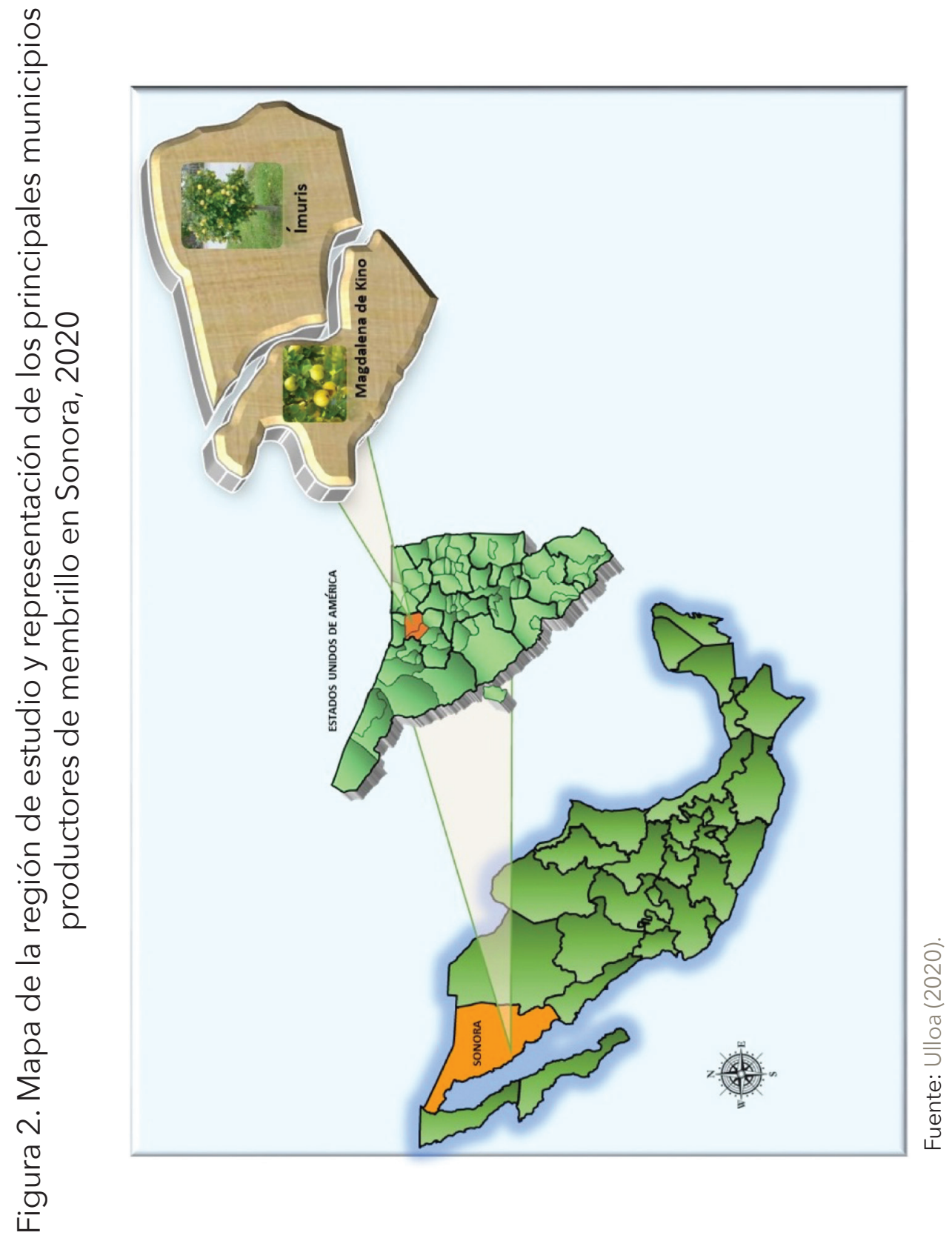


nes, en particular para movilizar el insumo principal de la PAA: las frutas que habrán de transformarse en CM y CF. Aunque quedó limitado al tránsito local cuando se construyó la llamada Carretera Federal 15 en el siglo XX, continúa siendo ruta de peregrinaciones durante las ya citadas fiestas patronales y de circulación intrarregional.

Las comunidades que interactúan en la PAA son Magdalena de Kino, San Ignacio, Terrenate y La Mesa, las dos primeras pertenecientes al municipio de Magdalena de Kino y las dos últimas al de Ímuris (véase figura 2).

Se trata de una zona separada administrativa y políticamente en dos municipios contiguos, con fuertes vínculos históricos, económicos y culturales que suman una extensión territorial de 3412.04 kilómetros cuadrados $\left(\mathrm{km}^{2}\right)$. Tiene un clima seco semicálido, un suelo semiplano adecuado para la agricultura; sin embargo, la escasez de agua reduce su potencial. Su precipitación media anual es de 367.1 milímetros $(\mathrm{mm})$. Buena parte de su vegetación está constituida por pastizales y matorral desértico micrófilo (León, Hernández, Andablo y Ulloa, 2006). El río Magdalena y sus afluentes atraviesan la región en su mayor parte (INEGI, 2009a y 2009b), lo que tal vez ha resultado determinante para el establecimiento de las actuales comunidades y para el trazo del antiguo camino real que avanza paralelo al río.

En ambos municipios predominan las actividades económicas comerciales y de servicios, además de las prácticas industriales, mineras, agrícolas y ganaderas (Corella, 2010; Secretaría de Agricultura, Ganadería, Desarrollo Rural, Pesca y Alimentación [SAGARPA], 2017). Otro rasgo distintivo es su cercanía a la frontera con Estados Unidos, lo que también le permite proyectar sus alimentos artesanales a los mercados de la nostalgia del vecino país, tanto por las peregrinaciones como por ser un lugar de paso obligado para muchos viajantes que transitan por la Carretera Federal 15. Los principales datos socioeconómicos del territorio se presentan en la tabla 1.

Tabla 1. Datos sociodemográficos

\begin{tabular}{|c|c|c|}
\hline \multirow{2}{*}{ Indicador } & \multicolumn{2}{|c|}{ Municipio } \\
\cline { 2 - 3 } & \multicolumn{1}{|c|}{ Ímuris } & Magdalena \\
\hline \multicolumn{2}{|c|}{ Población } \\
\hline Núm. de habitantes (2015) & 12812 & 31180 \\
\hline \multicolumn{3}{|c|}{20} \\
\hline Población ocupada por el sector económico en 2017 (\%) \\
\hline Primario & 30 & 82 \\
\hline Secundario & 18 & 15 \\
\hline Comercio & 31 & 34 \\
\hline
\end{tabular}

Fuente: elaboración propia con base en datos del INEGI (2017 y 2020). 
Dimensión histórica

Los primeros pobladores de la región fueron pimas altos y pápagos asentados en los márgenes de los ríos. En el siglo XVII arribó un grupo de misioneros jesuitas a evangelizar a los indios. Este acontecimiento fincó las bases de un profundo cambio a escala regional mediante la doctrina, la educación y, cuando fue necesario, la imposición (Corella, 2010). Fueron fundados cada uno de los poblados que aún subsisten interconectados (véase figura 3 ).

Una de las principales aportaciones jesuitas fue la introducción de los árboles frutales, sembrados en cada misión, entre los que destacan membrillo, granada, higo negro, higo misionero, durazno, manzano y chabacano (Corella, 2010; García-Yánez y Emmanuel, 2020).

La peculiaridad de un alimento de naturaleza artesanal deriva de su calidad ligada al territorio, conformada por elementos tangibles e intangibles. Además de la gran importancia histórica, cultural y económica del antiguo camino real al facilitar la articulación de diversos procesos que dan identidad al territorio, se caracteriza por sus hermosos paisajes naturales (cerro de La Cruz, río Magdalena, arboledas y cultivos), el patrimonio cultural (arte rupestre y petroglifos), las construcciones antiguas (molino de Pierson, templos, plazas), las festividades religiosas mezcladas con tradiciones culinarias (Corella, 2020), como la celebración del día de San Isidro Labrador a lo largo del río, con la degustación de pozole de trigo.

La producción de CM y de CF por diversas familias a través de los años está dentro de las principales tradiciones culinarias. La mayoría de las UFPAA tienen más de cuatro décadas en funcionamiento. A pesar de que esta actividad no es su principal fuente de ingresos, continúan practicándola por el gran apego emocional que le tienen los productores.

Dimensión técnico-productiva: el saber hacer

En las entrevistas realizadas a los integrantes de las UFPAA, se destacó que entre las principales razones por las cuales continúan con la PAA son la tradición heredada de sus antepasados, la satisfacción personal, su conocimiento sobre los procesos (saber hacer), la posibilidad de autoabastecerse de su insumo natural -aunque sólo en algunos casos- y, por supuesto, los beneficios económicos.

El estudio se enfocó en dos AA. La cajeta de membrillo, nombre que se le dio en la región a un dulce derivado de la pulpa del membrillo y azúcar, cocido con leña de mezquite, cuyo proceso dura alrededor de 3.5 horas. Su presentación tradicional es en bloques de 250 gramos, más o menos, envueltos en papel de celofán transparente. Y las conservas de frutas (frutas en almíbar, jaleas y mermeladas) están elaboradas con durazno, chabacano e higo, envasadas en frascos de cristal con capacidad de entre 250 y 1000 mililitros $(\mathrm{ml})$. Su procesamiento varía dependiendo del tipo de conserva; su base es el cocimiento de la fruta y posterior adición de almíbar. Ambos procesos son representativos de la región y se consideran el resultado de prácticas ancestrales de conservación 


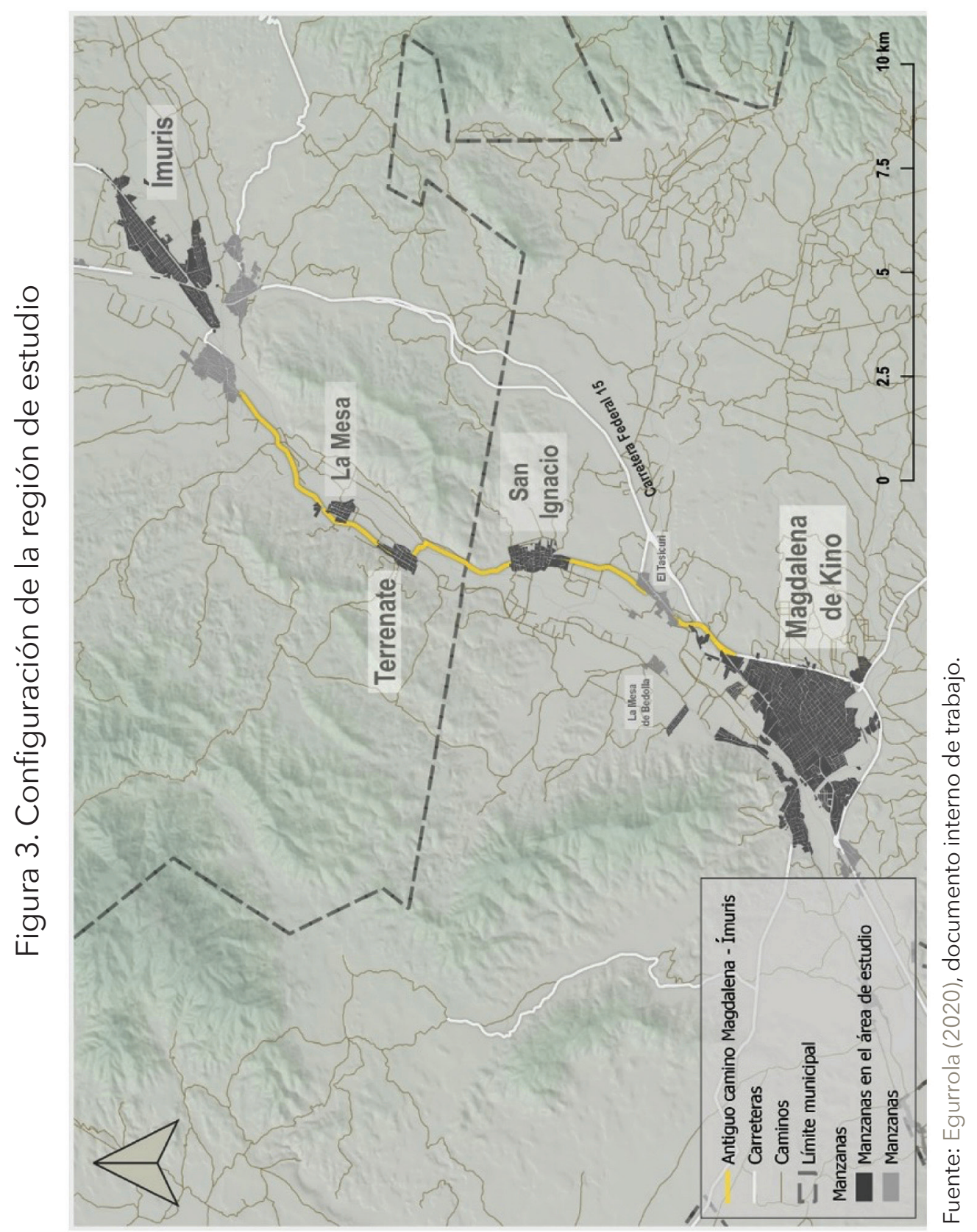


de frutas cosechadas en el territorio mediante la adición mínima de ingredientes externos y conservadores artificiales, lo cual demuestra el conocimiento antiguo sobre la elaboración y la transformación de alimentos (Camacho et al., 2019; Ortega, Vásquez, Flores y Núñez, 2017). Dicho saber hacer -traducido a prácticas productivas, de transformación, de conservación y de empaquetado para su venta- se conjuga con elementos propios del ecosistema del territorio para configurar la tipicidad de los productos identificada por las UFPAA. A continuación, se destaca la relevancia del insumo principal (frutas), producido en la localidad que asegura la tipicidad de los AA, según las opiniones de las UFPAA (véase tabla 2).

Tabla 2. UFPAA: valoración de la calidad de los AA en relación con el abastecimiento del insumo local (frutas)

\begin{tabular}{|c|c|c|c|}
\hline UFPAA Categoría & $\begin{array}{l}\text { Altamente } \\
\text { integradas }\end{array}$ & $\begin{array}{l}\text { Medianamente } \\
\text { integradas }\end{array}$ & $\begin{array}{c}\text { No } \\
\text { integradas }\end{array}$ \\
\hline $\begin{array}{l}\text { Elementos que } \\
\text { determinan la } \\
\text { calidad del AA }\end{array}$ & $\begin{array}{l}\text { Condiciones } \\
\text { climatológicas }\end{array}$ & $\begin{array}{l}\text { Propiedades } \\
\text { de la tierra }\end{array}$ & $\begin{array}{ll}\text { - } & \text { Propiedades } \\
\text { - } & \text { de la tierra } \\
\text { - } & \text { Condiciones } \\
\text { - } & \text { climatológicas } \\
\end{array}$ \\
\hline $\begin{array}{c}\text { Origen del } \\
\text { insumo principal }\end{array}$ & $\begin{array}{ll}\text { - } & \text { San Ignacio } \\
\text { - } & \text { Cucurpe } \\
\text { - } & \text { Tubutama } \\
\text { - } & \text { Ímuris } \\
\text { - } & \text { Arizpe } \\
\end{array}$ & $\begin{array}{ll}\text { - } & \text { San Ignacio } \\
\text { - } & \text { Cucurpe } \\
\text { - } & \text { Cananea }\end{array}$ & San Ignacio \\
\hline $\begin{array}{c}\text { Fechas de cosecha } \\
\text { de los principales } \\
\text { frutales utilizados } \\
\text { para la PAA }\end{array}$ & $\begin{array}{l}\text { - Agosto-octubre } \\
\text { - Agosto-noviembre }\end{array}$ & $\begin{array}{l}\text { - A partir de mayo } \\
\text { - Julio-noviembre }\end{array}$ & - Mayo-septiembre \\
\hline $\begin{array}{l}\text { Principales } \\
\text { características de } \\
\text { las frutas locales }\end{array}$ & 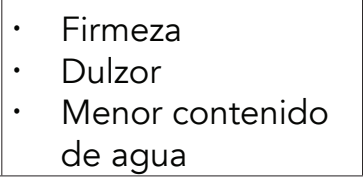 & $\begin{array}{ll}\text { - } & \text { Firmeza } \\
\text { - } & \text { Dulzor } \\
\text { - } & \text { Menor contenido agua } \\
\end{array}$ & \\
\hline
\end{tabular}

Fuente: elaboración propia con base en las entrevistas realizadas del 15 de abril al 27 de julio de 2019 en la región de estudio.

El membrillo es considerado el fruto emblemático de la región. Tanto los productores como los consumidores lo identifican como el principal insumo de la CM. En la actualidad se produce en huertas familiares, junto a otros frutales, que han logrado perdurar a lo largo del tiempo; no obstante, esta producción no es suficiente.

Dada la heterogeneidad que prevalece entre las UFPAA, aun siendo un universo de 26 sujetos con operaciones en pequeña escala, se consideró conveniente separarlas según sus niveles de integración productiva (Nigh y González, 2015; Turner y Davidson-Hunt, 2016), para encontrar sus diferencias no sólo en 
sus procesos, sino también en sus perspectivas sobre la PAA en general y sobre su potencial para contribuir al desarrollo de la región. De tal diferenciación se obtuvieron las siguientes categorías:

Las UFPAA altamente integradas (7) son los productores propietarios de huertos de membrillo, cuyo fruto se destina a la elaboración artesanal de CM para la venta, por lo general de manera directa al consumidor; es decir, intervienen en tres eslabones de la cadena productiva: producción primaria, transformación y comercialización.

Las UFPAA medianamente integradas (13) se dedican a la elaboración tanto de CF como de CM. Participan en la transformación y en la comercialización de alimentos artesanales. No producir la fruta les da la flexibilidad de adquirirla en distintos lugares de la región o en regiones vecinas. Pueden elaborar diversos productos y distribuirlos en distintos puntos de venta y tiendas de productos regionales, en particular de Magdalena de Kino. Constituyen el grupo social más numeroso, lo cual era de esperarse en la medida en que, como se verá más adelante, la producción local de frutas es mínima. En este grupo también se registra la mayor diversidad de alimentos artesanales.

Las UFPAA no integradas (6) están representadas por los propietarios de tiendas de productos regionales y puntos de venta. Se dedican a la compraventa de alimentos artesanales, pero comparten elementos identitarios con las otras dos categorías.

Las UFPAA consideran que las condiciones climatológicas y las propiedades de la tierra son condicionantes de la calidad de su insumo. En ese sentido, el jefe del Distrito de Desarrollo Rural 140 (DDR-140) afirma que “los niveles de minerales y sales en el agua son muy buenos, por lo que no es necesaria la adición de grandes cantidades de insumos artificiales para la producción de frutas y vegetales". Por su parte, Macías, Grijalva y Robles (2007, p. 37) determinaron, con base en los análisis fisicoquímicos realizados en los suelos de la región, que éstos son aptos para producir hortalizas, forrajes y frutales. Además, las temperaturas estacionales, los niveles de humedad, el viento y la exposición al sol determinan las características específicas del producto (Vandecandelaere et al., 2010).

Dada la relevancia del abasto local de frutas, se exploró el historial de los frutales utilizados en la PAA (véase figura 4).

Si bien estos datos son estatales, las condiciones climatológicas y físicas permiten deducir que éstos pudieron corresponder a la producción de la región de estudio y de los puntos circunvecinos, ya que los registros de producción de membrillo indican que los municipios de Magdalena de Kino e Ímuris en conjunto tuvieron una participación en la producción estatal de 62\% en 1950, 50\% en 1960 y 46\% en 1970 (Ulloa, 2020).

Las UFPAA atribuyen el decremento de la producción a las sequías recurrentes. El actual jefe del DDR-140 (SADER) menciona las enfermedades de las plantas, la falta de mercado y la sequía del río. El técnico retirado de la actual SADER, que se encontraba activo en los años del auge, precisó que el inicio del declive se dio a partir de la década de 1990, debido a la escasez de agua y a la presencia de enfermedades en los frutales. 
Figura 4. Historial de producción de chabacano, durazno e higo en Sonora, 1980-2000

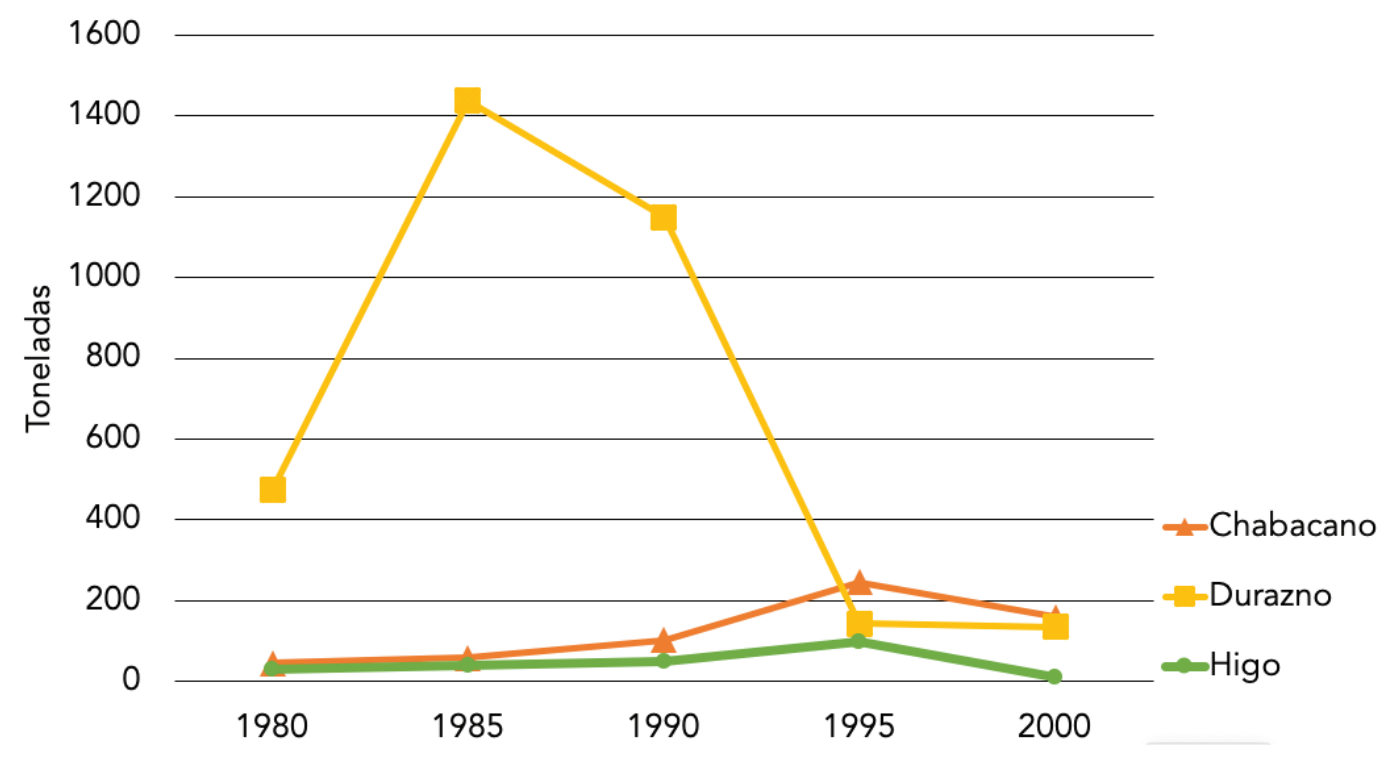

Fuente: Ulloa (2020).

Figura 5. Producción de membrillo en Sonora, 1950-2019

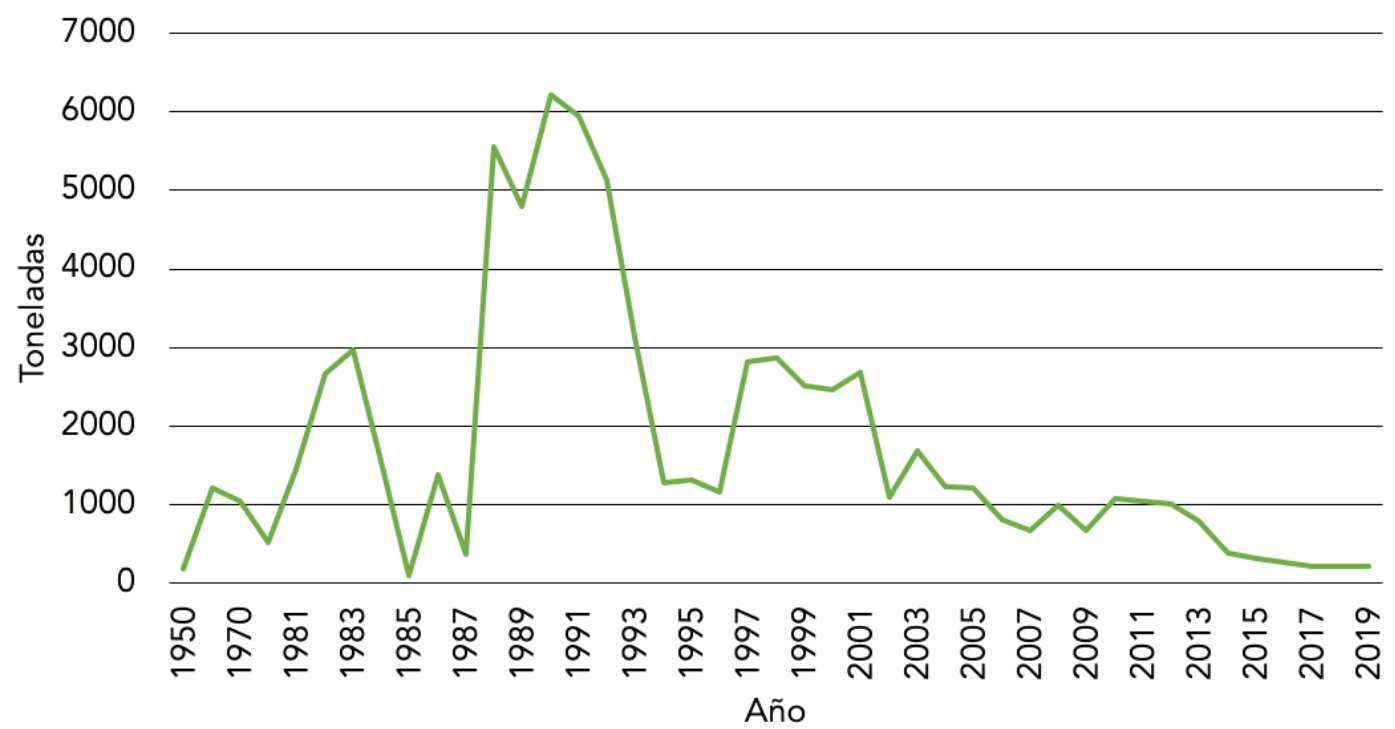

Fuente: elaboración propia con base en la Estadística Producción Agrícola (2020).

A partir de estas afirmaciones, se revisaron las precipitaciones registradas entre 1946 y 2013 en la estación El Ranchito, Ímuris (véase figura 6). 


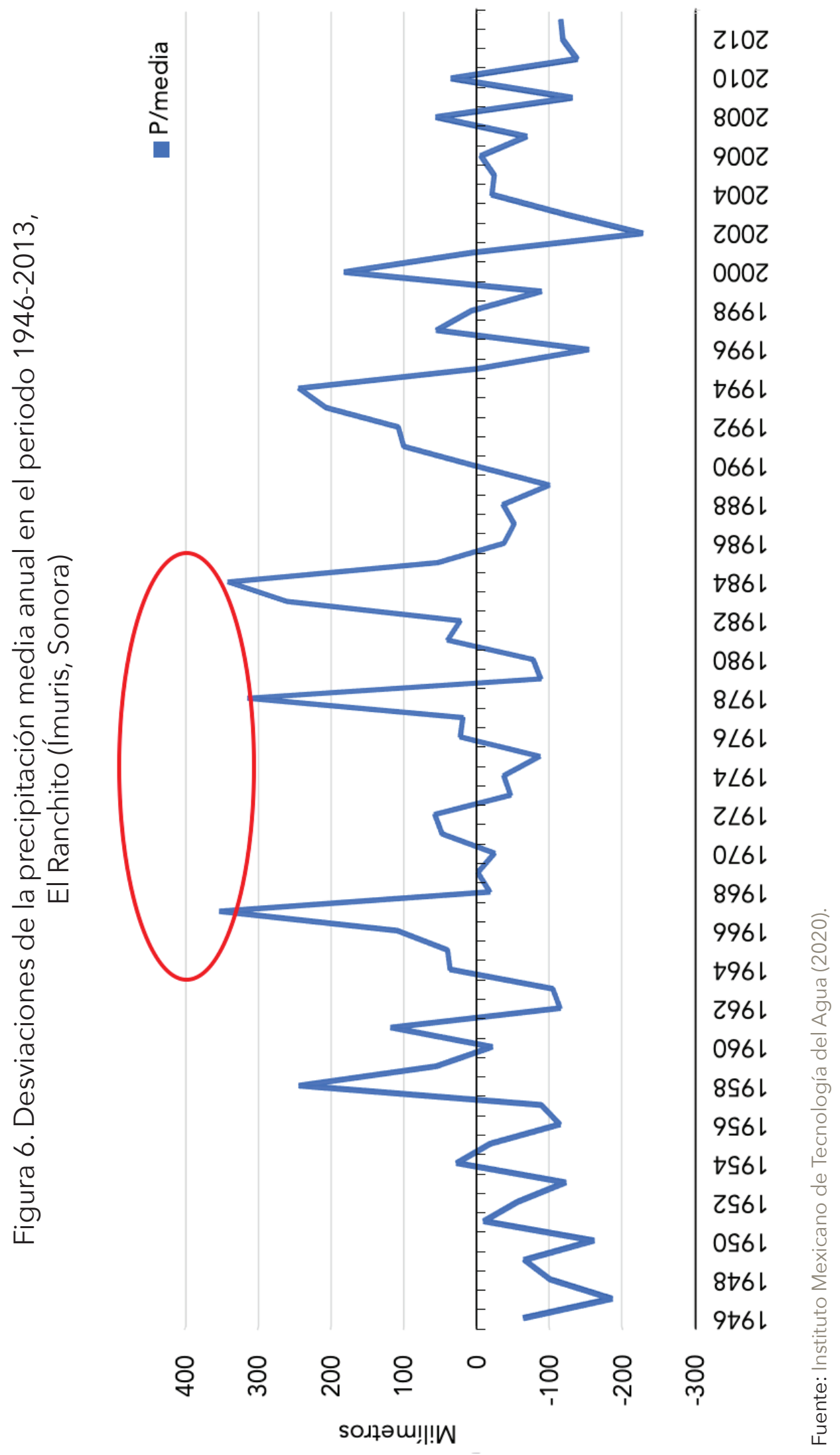


El comportamiento observado es típico de una región con un clima semiseco. De hecho, no obstante la convicción de los informantes sobre el peso determinante de la sequía en la caída de la producción local, la figura 6 muestra que entre 1946 y 1957 los rangos de lluvia fueron todavía menores. Esta percepción de los informantes se justifica en virtud de que aún no habían nacido cuando tuvo lugar la etapa más crítica de la sequía. El contraste de la gráfica de producción con la de precipitaciones muestra la coincidencia de los años de mayores lluvias, con los de mayor producción 1988-1994 (véase figura 5).

Una relación que parece más contundente es la caída de la producción local con la apertura comercial, si bien sólo el jefe del Distrito de SADER y el técnico retirado señalaron los problemas de mercado como uno de los factores desencadenantes de la caída de la producción. Su decremento coincide con la transformación del paradigma económico acontecido en el país y en el mundo subdesarrollado para atender la alteración estructural demandada por la globalización económica y en particular agroalimentaria (McMichael, 2009), lo que trajo consigo el desplazamiento de la producción agrícola de pequeña escala.

La participación de México en el Acuerdo General sobre Aranceles Aduaneros y Comercio (GATT, por sus siglas en inglés) en 1986, la firma del Tratado de Libre Comercio de América del Norte (TLCAN) en 1994 y la desregulación del Estado dieron paso al incremento de las importaciones de alimentos. La sobreoferta de fruta a raíz de la apertura de la frontera presionó el valor interno a la baja. El técnico retirado entrevistado comentó que los propietarios de huertos de la región no lograron competir con el mercado de importaciones de frutas, ya que el precio del mercado era tan bajo que no alcanzaban a cubrir sus costos de producción. Se inauguraba en ese entonces un paradigma económico que consideró no competitivos a estos productores, por ser de pequeña escala y porque se orientan al mercado interno, por lo que a ese modelo convenía más importar los productos que ellos producen, que asegurar la vigencia de esa forma de producción.

\section{Dimensión institucional}

Esta dimensión hace referencia a las relaciones y andamiajes que respaldan y normalizan los SIAL (Muchnik, 2006). En este estudio, el análisis se centra en las relaciones que establecen las UFPAA entre sí y con otros actores, ya sean de la cadena de valor o de su entorno gubernamental y normativo. Los resultados mostraron la ausencia total de estrategias organizativas por parte de las UFPAA y una escasa identidad gremial; cada UFPAA se concibe a sí misma como entidad aislada (véase tabla 3).

La información sobre el ámbito normativo e institucional se obtuvo de las versiones de las propias UFPAA y de los servidores públicos entrevistados. Aquí destaca el doble discurso oficial, pues se reconoce que la PAA es emblema de la región, se resalta su valor cultural, histórico e incluso económico, pero, a la vez, las opiniones de los servidores públicos evidenciaron su gran descono- 
cimiento del tema. Así lo constata el desmantelamiento en 2004 de la unidad experimental del Instituto Nacional de Investigaciones Forestales, Agrícolas y Pecuarias (INIFAP), que realizaba estudios fundamentales para combatir las enfermedades de los frutales. Otras evidencias son la ausencia de políticas públicas de fomento y protección, de programas institucionales de atención a sus problemas específicos y la carencia de registros sobre la PAA.

Tabla 3. Actores involucrados en la PAA de CM y CF

\begin{tabular}{|c|c|c|c|c|}
\hline \multicolumn{2}{|c|}{ Categorías de los actores } & \multicolumn{2}{|r|}{ Características } & Motivos \\
\hline a) & $\begin{array}{l}\text { Productores de } \\
\text { materia prima }\end{array}$ & a) & $\begin{array}{l}\text { Combinan sus actividades } \\
\text { principales (agricultura y } \\
\text { ganadería) con la produc- } \\
\text { ción de frutales }\end{array}$ & $\begin{array}{l}\text { a) Preservan la tradición y } \\
\text { el saber hacer genera- } \\
\text { cional }\end{array}$ \\
\hline b) & $\begin{array}{l}\text { Comerciantes } \\
\text { de insumos }\end{array}$ & b) & $\begin{array}{l}\text { Centros de mayoreo, su- } \\
\text { permercados y papelerías } \\
\text { locales }\end{array}$ & $\begin{array}{l}\text { b) Proveen el insumo arti- } \\
\text { ficial y material de em- } \\
\text { paquetado }\end{array}$ \\
\hline c) & Transformadores & c) & $\begin{array}{l}\text { Se dedican a la PAA sólo } \\
\text { durante la temporada de } \\
\text { los diferentes insumos natu- } \\
\text { rales utilizados para elabo- } \\
\text { rar AA }\end{array}$ & $\begin{array}{l}\text { c) Gran arraigo emocional } \\
\text { a la PAA }\end{array}$ \\
\hline d) & Comerciantes de AA & d) & $\begin{array}{l}\text { Dueños de puntos de venta } \\
\text { y tiendas de productos re- } \\
\text { gionales; compraventa de } \\
\text { productos tradicionales }\end{array}$ & $\begin{array}{l}\text { d) Promotores de las tradi- } \\
\text { ciones culinarias de la } \\
\text { región }\end{array}$ \\
\hline e) & $\begin{array}{l}\text { Oficina de Desarrollo } \\
\text { Económico y Turismo } \\
\text { Municipal }\end{array}$ & e) & $\begin{array}{l}\text { Desorganización de sus ac- } \\
\text { tividades, falta de datos y } \\
\text { poca aplicación de recursos }\end{array}$ & $\begin{array}{l}\text { e) Reconocen que la PAA } \\
\text { es sello identitario de la } \\
\text { región, pero no fomen- } \\
\text { tan ni promueven su } \\
\text { impulso }\end{array}$ \\
\hline f) & SADER & f) & $\begin{array}{l}\text { Poco interés en los } \\
\text { pequeños productores; des- } \\
\text { motivación de rescate a los } \\
\text { frutales de la región }\end{array}$ & $\begin{array}{l}\text { f) Reconocen el potencial } \\
\text { productivo de la re- } \\
\text { gión, pero no fomentan } \\
\text { ni promueven su im- } \\
\text { pulso }\end{array}$ \\
\hline g) & Consumidores & g) & $\begin{array}{l}\text { Principalmente personas } \\
\text { mayores de } 45 \text { años; forá- } \\
\text { neos y de ingresos medios }\end{array}$ & $\begin{array}{l}\text { g) Valoran el sabor de los } \\
\text { AA Su consumo es más } \\
\text { relevante para los jó- } \\
\text { venes }\end{array}$ \\
\hline
\end{tabular}

Fuente: elaboración propia con base en resultados de las entrevistas y de Vandecandelaere et al. (2010). 
Esta debilidad institucional puede explicarse en dos planos: en el estructural, porque se marginaron por completo las actividades de la PAA en el régimen alimentario corporativo, de ahí la falta de interés gubernamental en preservarlas; y en el plano local, debido a que las UFPAA no realizaron acción colectiva. Las entrevistas a sus integrantes también evidenciaron contradicciones entre la necesidad de unidad gremial y la desconfianza de definir y proponer objetivos comunes. El enfoque de los SIAL concede particular relevancia a este punto (Hernández y Ochoa, 2012). Sin la actuación de organizaciones que faciliten e institucionalicen la coordinación horizontal y vertical entre los diversos actores que participan en la PAA, los atributos del territorio no se patrimonializan. Este asunto es crítico porque limita la capacidad de gestión, de negociación y de presión para lograr el reconocimiento de su actividad a las UFPAA.

\section{Dimensión alimenticia-consumo}

Según Muchnik (2006, p. 4), esta dimensión hace referencia a las relaciones sociales, culturales y económicas establecidas entre productor y consumidor, con lo que se resalta que el mercado de alimentos artesanales no se restringe a una interacción de compraventa (Bourdieu, 2005). Uno de los atributos de la PAA es que propicia la mayor cercanía entre el productor y el consumidor; es decir, éstos no son anónimos (McMichael, 2014), de ahí la necesidad de conocer los motivos de los consumidores para adquirir alimentos artesanales en la región de estudio.

En este punto se destaca el turismo como la actividad que dinamiza la PAA. Según los testimonios de las personas de las UFPAA, de los servidores públicos y por la posición geográfica y el significado cultural del territorio analizado, el turista es un consumidor protagónico. El hecho de que Magdalena de Kino haya sido declarada pueblo mágico en 2012 (Secretaría de Turismo [SECTUR], 2014), refuerza esa articulación.

El estudio partió de la caracterización de los consumidores para detallar cuáles perfiles mostraban mayor preferencia hacia los alimentos artesanales, las razones y la valoración del potencial de la PAA. Las variables consideradas fueron edad, escolaridad, ingresos, lugar de residencia y número de visitas al año. La selección de los informantes fue aleatoria. Por ello los bloques integrados a partir de la edad fueron proporcionalmente asimétricos y no comparables entre sí; por lo tanto, los datos que se muestran en la tabla 4 reflejan los pesos específicos de cada reactivo al interior de cada segmento.

Esta división de los informantes tiene como propósito diferenciar las opiniones de las nuevas generaciones de consumidores, quienes parecen ser el grupo etario que está impulsando un consumo más reflexivo y comprometido (Rugren, 2017), variable que también se relaciona con un mayor nivel educativo y de ingresos.

En este estudio, sin embargo, la mayor parte de los consumidores encuestados rebasaron los 45 años, con un nivel de estudios básico y bajos ingresos económicos (véase tabla 4), los que prefieren primordialmente la CM y las CF artesanales por su sabor (véase tabla 6). 
Tabla 4. Perfil de los consumidores de AA

\begin{tabular}{|c|c|c|c|c|c|c|}
\hline Rangos de edad & \multicolumn{2}{|c|}{ Entre 18 y 29} & \multicolumn{2}{|c|}{ Entre 30 y 44} & \multicolumn{2}{|c|}{$>45$} \\
\hline \multirow[t]{2}{*}{ Totales } & $\#$ & $\%$ & $\#$ & $\%$ & $\#$ & $\%$ \\
\hline & 10 & 9 & 29 & 26 & 72 & 65 \\
\hline \multicolumn{7}{|l|}{ Escolaridad } \\
\hline Básica & 1 & 10 & 9 & 31 & 46 & 65 \\
\hline Bachillerato o profesional & 8 & 80 & 19 & 65 & 22 & 31 \\
\hline Posgrado & 1 & 10 & 1 & 4 & 0 & 0 \\
\hline Ninguna & 0 & 0 & 0 & 0 & 3 & 4 \\
\hline \multicolumn{7}{|l|}{ Ingresos } \\
\hline Sin ingresos & 4 & 40 & 1 & 3 & 12 & 17 \\
\hline$<3037$ & 0 & 0 & 0 & 0 & 3 & 4 \\
\hline Entre 3037 y 5366 & 2 & 20 & 6 & 21 & 34 & 49 \\
\hline Entre 7142 y 8898 & 3 & 30 & 10 & 34 & 13 & 18 \\
\hline Entre 10772 y 12985 & 1 & 10 & 8 & 28 & 4 & 5 \\
\hline$>15754$ & 0 & 0 & 4 & 14 & 5 & 7 \\
\hline \multicolumn{7}{|l|}{ Residencia } \\
\hline Local & 0 & 0 & 4 & 14 & 12 & 17 \\
\hline Foránea & 8 & 80 & 20 & 69 & 47 & 66 \\
\hline Extranjera & 1 & 10 & 2 & 7 & 2 & 3 \\
\hline Sin respuesta & 1 & 10 & 3 & 10 & 10 & 14 \\
\hline \multicolumn{7}{|l|}{ Número de visitas al año } \\
\hline$<2$ & 6 & 60 & 11 & 38 & 49 & 69 \\
\hline Entre 3 y 5 & 3 & 30 & 5 & 17 & 6 & 9 \\
\hline$>5$ & 1 & 10 & 9 & 31 & 3 & 4 \\
\hline Sin respuesta & 0 & 0 & 4 & 14 & 13 & 18 \\
\hline
\end{tabular}

Fuente: elaboración propia con base en los resultados de la encuesta.

Tabla 5. Consumo de AA: 111

\begin{tabular}{|c|c|c|c|c|c|c|c|}
\hline Edad & Frecuente & $\%$ & Ocasional & $\%$ & Nunca & $\%$ & \\
\hline Entre 18 y 29 & 1 & 10 & 8 & 80 & 1 & 10 & 10 \\
\hline Entre 30 y 45 & 6 & 21 & 23 & 79 & & 0 & 29 \\
\hline$>45$ & 12 & 17 & 58 & 81 & 2 & 3 & 72 \\
\hline
\end{tabular}

Fuente: elaboración propia con base en los resultados de la encuesta. 
Tabla 6. Razones para consumir AA: 111

\begin{tabular}{|c|c|c|c|c|c|c|c|}
\hline Edad & Sabor & $\%$ & Tradición & $\%$ & Apoyo & $\%$ & \\
\hline Entre 18 y 29 & 5 & 50 & 5 & 50 & 1 & 10 & 10 \\
\hline Entre 30 y 45 & 20 & 69 & 11 & 38 & 8 & 28 & 29 \\
\hline$>45$ & 55 & 76 & 14 & 19 & 21 & 29 & 72 \\
\hline & 80 & & 30 & & 30 & & \\
\hline
\end{tabular}

Fuente: elaboración propia con base en los resultados de la encuesta.

Con respecto a la valoración de la PAA sobre su importancia para las nuevas generaciones, para la mejora económica de las familias locales y como motor de desarrollo regional, se observa una alta valoración en los tres grupos de edad, pero los desacuerdos e indecisiones fueron más altos en la generación de los consumidores mayores de 45 años (véanse tablas 7,8 y 9).

Tabla 7. Importancia del consumo de AA para nuevas generaciones:

111

\begin{tabular}{|c|c|c|c|c|c|c|c|}
\hline Edad & Acuerdo & $\%$ & Desacuerdo & $\%$ & Indeciso & $\%$ & \\
\hline Entre 18 y 29 & 5 & 50 & 1 & 10 & 4 & 40 & 10 \\
\hline Entre 30 y 44 & 20 & 69 & 5 & 17 & 4 & 14 & 29 \\
\hline$>45$ & 34 & 47 & 23 & 32 & 15 & 21 & 72 \\
\hline
\end{tabular}

Fuente: elaboración propia con base en los resultados de la encuesta.

Tabla 8. PAA: Importancia económica: 111

\begin{tabular}{|c|c|c|c|c|c|}
\hline Edad & Muy importante & $\%$ & Moderada & $\%$ & \\
\hline Entre 18 y 29 & 9 & 90 & 1 & 10 & 10 \\
\hline Entre 30 y44 & 17 & 59 & 12 & 41 & 29 \\
\hline$>45$ & 55 & 76 & 16 & 22 & 72 \\
\hline
\end{tabular}

Fuente: elaboración propia con base en los resultados de la encuesta.

Tabla 9. PAA: Potencial para el desarrollo regional: 111

\begin{tabular}{|c|c|c|c|c|c|c|c|}
\hline Edad & Acuerdo & $\%$ & Desacuerdo & $\%$ & Indeciso & $\%$ & \\
\hline Entre 18 y 29 & 10 & 100 & 0 & 0 & 0 & 0 & 10 \\
\hline Entre 30 y 44 & 22 & 76 & 0 & 0 & 7 & 24 & 29 \\
\hline$>45$ & 65 & 90 & 2 & 3 & 5 & 7 & 72 \\
\hline
\end{tabular}

Fuente: elaboración propia con base en los resultados de la encuesta. 
La solicitud de comentarios finales fue atendida sólo por $25 \%$ de los encuestados. De éstos, $87 \%$ pertenece al grupo de personas mayores a 45 años; $14 \%$, al grupo de entre 30 y 44 y nadie de menor edad respondió esta solicitud. Las expresiones esbozadas destacan el beneplácito de los consumidores por la tipicidad de los alimentos artesanales y su vínculo con las fiestas patronales.

\section{Oportunidades y desafíos para la producción artesanal de CM y de CF identificados por las UFPAA. Una discusión a partir de la TRA}

La adaptación de las dinámicas territoriales del enfoque de los SIAL propuestas por Muchnik (2006) hicieron posible registrar los elementos territoriales, históricos, institucionales (organización colectiva y entorno gubernamental y normativo), técnicos (saber hacer) y alimenticios (consumo) para reconocer las principales oportunidades y los desafíos que enfrenta la producción artesanal de CM y de CF en la región de estudio, en el marco actual de la coyuntura alimentaria. Al respecto, en esta sección se exponen las percepciones de los miembros de las UFPAA sobre sus expectativas en el contexto analizado.

Este ejercicio se realizó diferenciando a las UFPAA con base en su grado de integración productiva, bajo el supuesto de que eso generaría perspectivas diferenciadas. No obstante, las respuestas de las personas de las UFPAA reflejaron una visión compartida en torno a los atributos que potencialmente permitirían que la PAA patrimonialice la región de estudio. Tal es el caso del valor de la tipicidad de la CM y de las CF y su estrecha relación con el turismo, opinión secundada tanto por los servidores públicos entrevistados, como por los consumidores que participaron en la encuesta.

En teoría, esta percepción se puede explicar como la expresión local de la emergencia de un nuevo paradigma alimentario, alternativo al sistema alimentario dominante (McMichael, 2014), que conjuga el consumo reflexivo, la agricultura cívica y el turismo con la causa para la revalorización de actividades que habían sido desplazadas por la industrialización alimentaria.

Por otro lado, las UFPAA también coincidieron al reconocer que su desafío primordial es la escasez de fruta producida en la localidad, su principal materia prima. Como se constató con base en las estimaciones de las series de producción (véanse figuras 4 y 5), la región de estudio experimentó un marcado descenso en su población de frutales. Los actores locales que participaron en el estudio atribuyeron esta situación a la escasez de agua y a la recurrencia de enfermedades que afectaron plantaciones cuyos antecedentes datan de la llegada de los misioneros jesuitas a la región. Empero, no señalaron la apertura comercial ni los cambios en las políticas para el campo que orientaron las subvenciones y los apoyos hacia los cultivos de exportación -sucesos que coinciden en el tiempo con la desaparición casi total de las huertas regionales-. Sólo uno de los informantes hizo referencia al desplome de los precios de la fruta pero como hecho aislado, sin injerencia en el derrumbe de la producción frutícola. 
Es a raíz de la interpretación de tales acontecimientos con el marco analítico de la TRA (Friedmann y McMichael, 1989; McMichael, 2009 y 2014) que la debacle frutícola de Magdalena de Kino puede explicarse como resultado de la reconfiguración de los espacios productivos y de las relaciones de producción promovidas por el Estado mexicano para alinearse a la globalización alimentaria. Eso significó el abandono de las antiguas producciones locales orientadas al mercado interno y la reconversión de las tierras de cultivo hacia cultivos que maximizasen las ganancias y se insertaran en los mercados internacionales a costa del desarrollo local. Dicha reorientación de las prioridades nacionales dejó desprotegidos a los propietarios de huertos familiares dedicados a la transformación artesanal del producto, quienes, a pesar de la exclusión sufrida durante décadas, continuaron resistiendo para preservar una actividad que no sólo les representa una fuente de ingresos, muchas veces complementaria, sino que también es motivo de orgullo y prestigio familiar. En este escenario confluyen la creciente demanda de cierto perfil de consumidores de alimentos menos procesados y con mayor valor cultural, con la revaloración de los alimentos no procesados, ahora enarbolados por múltiples movimientos socioalimentarios alrededor del mundo como parte de un paradigma alternativo a la globalización alimentaria (McMichael, 2014).

La cotidianidad de las UFPAA también enfrenta desafíos relevantes para su actividad. Los miembros de las UFPAA altamente integradas señalaron que el robo del membrillo, aun antes del tiempo de cosecha, es una amenaza preocupante para su actividad. Los de las medianamente integradas añadieron la escasez de agua y las limitaciones económicas para mantener y ampliar su producción. Los de las UFPAA no integradas refirieron que los obstáculos son la delincuencia, la corrupción y los altos impuestos aplicados por parte del gobierno municipal, y advirtieron que la regulación sanitaria y el Sistema de Administración Tributaria (SAT) entorpecen el crecimiento de su negocio.

Aunque dichas situaciones no son controlables por las UFPAA, el robo del insumo es alarmante porque desincentiva la producción y pone en riesgo la tipicidad de la PAA y la actividad misma. Lo más grave es que algunas UFPAA medianamente integradas adquieren la fruta sustraída, lo que evidencia la falta de solidaridad y cooperación entre las familias. Situación como la descrita da testimonio de la falta de cohesión social y del debilitamiento de la confianza entre las UFPAA, lo que obstaculiza la conjunción de esfuerzos para activar los SIAL de alimentos artesanales en la región, en una coyuntura que podría ser por demás prometedora si se aprovechase el conjunto de atributos de la región -que fueron reseñados en el apartado anterior- para responder de manera integral a las expectativas de los consumidores.

\section{Conclusiones}

Con el propósito de especificar las oportunidades y los desafíos de la PAA de la región de Magdalena de Kino, Sonora, en el escenario alimentario contemporáneo, en este estudio se analizaron las dinámicas territoriales que se articulan 
a esta actividad, utilizando el enfoque de los SIAL. Las expectativas de los integrantes de las UFPAA y las percepciones de los consumidores y de los servidores públicos locales vinculados a la PAA se interpretaron y se contextualizaron teniendo como marco de referencia los cambios estructurales del sistema alimentario en su proceso de globalización, abordados por la TRA (Friedmann y McMichael, 1989; McMichael, 2009 y 2014).

Se concluye que las familias dedicadas a la producción de CM y de CF en la región de Magdalena de Kino tienen ante sí una posibilidad de desarrollo muy distinta a la de las expectativas creadas por el régimen alimentario corporativo o globalizado (McMichael, 2009; Otero, 2013) y promovidas por las políticas públicas mexicanas durante las últimas tres décadas. Los elementos que antes se tomaban como señales de atraso, como la no industrialización y la no estandarización de los procesos, el mantenimiento de las pequeñas escalas, la tipicidad y la calidad anclada de forma ecológica al territorio, ahora son herramientas al alcance de las familias para competir en los mercados. Está claro que las UFPAA han sobrevivido, pese a lo adverso de su entorno, gracias a sus esfuerzos para preservar sus métodos de producción representativos, con la intención de mantener vivas sus tradiciones (Camacho et al., 2019; Domínguez-López et al., 2011).

La ruta hacia este propósito - fortalecer lo artesanal de las CM y de las CF y otros alimentos cuya calidad esté anclada al territorio- debe pasar de manera ineludible por el rescate de la producción local de frutales, condición sine qua non para conservar la tipicidad de sus productos. En la actualidad, la agroecología, sumada al empleo de tecnologías ahorradoras de agua, se erige como una alternativa viable para reactivar el establecimiento de huertos que atiendan la demanda de CM y de CF. Hay técnicas que permiten la recuperación de suelos y la atención a las enfermedades de los frutales sin dañar el medio ambiente. Tres siglos de producción frutícola ofrecen suficiente evidencia de la capacidad de adaptación de estas especies al ecosistema regional y del desarrollo paralelo de un conocimiento local que hoy se puede rescatar, valorar y apuntalar gracias a las innovaciones agroecológicas.

En este esfuerzo, el turismo es una de las actividades que pueden consolidar de muchas formas la PAA. En medio del desierto sonorense, los paisajes naturales que enmarcan la ruta interna Ímuris-Magdalena de Kino parecen un oasis muy apreciado en esas latitudes. Los atractivos turísticos ya descritos, sumados a la posición estratégica de la región, que se ubica a 80 kilómetros de la frontera con Arizona, Estados Unidos, y el hecho de que se la reconoce como la región del membrillo, se conjugan para proyectar una potencial ruta gastronómica y turística en torno a este fruto, que puede combinarse con el desarrollo de una gastronomía regional ligada a la producción primaria local y a la elaboración de quesadillas, también muy peculiares de esta zona del país.

Los elementos hasta aquí descritos podrían ser componentes de una estrategia de desarrollo local asentada en la PAA, pero para que este engranaje se encamine hacia dicho cometido, la acción colectiva de los actores sociales clave, en este caso las UFPAA y sus aliados, constituye la piedra angular en esta historia y a la vez es su talón de Aquiles para activar los atributos territoriales 
documentados en este estudio. En efecto, mientras las UFPAA se conciban a sí mismas como unidades aisladas, difícilmente tendrán capacidad de gestión, de presión y de negociación para incidir en proyectos privados y en acciones gubernamentales de fomento y protección de la PAA. Es decir, el mayor desafío en esta trama está en las propias UFPAA y en su incapacidad de organizarse y liderar una estrategia de desarrollo fundamentada en la activación de las múltiples ventajas y atributos que ostenta su territorio.

Por último, este estudio comprueba la pertinencia de un marco referencial integrado por la teoría de los regímenes alimentarios para explicar el contexto en el que a los alimentos producidos de manera artesanal se los desplaza primero y luego se los reinserta a los imaginarios alimentarios (Arias, 2014) y se los legitima mediante los movimientos de resistencia impulsados por los productores de pequeña escala y los consumidores (McMichael, 2014). Así mismo, el enfoque de los SIAL fue de gran utilidad para determinar las articulaciones y las complementariedades entre la PAA y otras actividades tan diversas como la fruticultura y el turismo. También se pudo destacar la importancia del territorio como factor que añade un valor específico a los alimentos artesanales y cómo éstos contribuyen a la patrimonialización de éste, siempre y cuando se activen sus atributos mediante la acción colectiva de las UFPAA en conjunto con otros actores clave.

\section{Referencias}

Aguilar, E., Sacco, F., y Velleda, N. (2011). Productos locales de calidad, diversificación: nuevas estrategias de desarrollo en el mundo rural de España y Brasil. Estudios Sociológicos, 29(85), 189-214.

Arias, J. (2014). Un vertiginoso viaje etnohistórico dentro de los "imaginarios alimentarios" en el simbolismo del cacao en México. Anales de Antropología, 48(1), 79-95.

Avieli, N., y Cota, R. (2015). Las guerras del humus: comida local, récord Guinness y gastropolítica palestino-israelí. Estudios de Asia y África, 50(3), 569-591.

Ayón, G. (2010). El turismo cultural y religioso, factor estratégico para el desarrollo de la actividad turística en Magdalena de Kino, Sonora (tesis de maestría). Centro de Investigación en Alimentación y Desarrollo A. C., Hermosillo, Sonora.

Barragán, E., y Ovando, P. (2019). ¿Cumplir normas mexicanas o mantener los alimentos artesanales? Reflexiones desde la sierra de Jalmich, región de origen del queso Cotija. En D. Chávez y T. Aguilar (coords.), Comunidad y Territorio: el caso del occidente michoacano (pp. 157-177). Ciudad de México: Universidad Nacional Autónoma de México.

Bertram, D. (2008). Likert Scales... are the meaning of life. Topic report. Recuperado de http: / / poincare.matf.bg.ac.rs/ kristina/topic-dane-likert.pdf 
Bessiere, J. (1998). Local development and heritage: traditional food and cuisine as tourist attractions in rural areas. Sociologia Ruralis, 38(1), 21-34.

Bowen, S. (2011). The importance of place: re-territorialising embeddedness. Sociologia Ruralis, 51(4), 325-348.

Bowen, S., y Mutersbaugh, T. (2014). Local or localized? Explore the contributions of Franco-Mediterranean agri-food theory to alternative food research. Agriculture and Human Values, 31(2), 201-2013.

Bourdieu, P. (2005). Principles of an Economic Anthropology. The Handbook of Economic Sociology. Nueva York: Princeton University Press.

Brunori, G.; Proost, J., y Rand, S. (2020). Small farms and innovation. Research in Rural Sociology and Development (25), 171-191.

Busch, L., y Bain, C. (2004). New! Improved? The transformation of the Global Agrifood System. Rural Sociology, 69(3), 321-346.

Calle, A., Gallar, D., y Candón, J. (2013). Agroecología política: la transición social hacia sistemas agroalimentarios sustentables. Revista de Economía Crítica (16), 244-277.

Calle, A., Soler, M., y Vara, I. (2009). La desafección del sistema agroalimentario: ciudadanía y redes sociales. En I Congreso Español de Sociología de la Alimentación (pp. 1-29). Gijón, España: INTERFACE.

Camacho, J., Cervantes, F., Cesín, A., y Palacios, M. (2019). Los alimentos artesanales y la modernidad alimentaria. Estudios Sociales, 29(53) 1-20.

Campbell, C. (2005). The craft consumer. culture, craft and consumption in a postmodern society. Journal of Consumer Culture, 5(1), 23-42.

Cambpell, H. (2009). Breaking new ground in food regime theory: corporate environmentalism, ecological feedbacks and the "food from somewhere" regime?, Agriculture and Human Values (26), 309-319.

Corella, A. (2010). Magdalena. No es un pueblo mágico, pero tiene magia. Monografía de Magdalena de Kino. Magdalena: Sonot Ediciones.

Corella, P. (2020). “La cara pintada" o “La cara Pinta” Terrenate, Ímuris, Sonora. Recuperado de https://www.facebook.com/LavozdelosHimeris/videos/732667237542185

Domínguez-López, A., Villanueva-Carvajal, A., Arriaga-Jordán, C., y Espinoza-Ortega, A. (2011). Alimentos artesanales y tradicionales: el queso Oaxaca como un caso de estudio del Centro de México. Estudios Sociales, 19(38), 166-193.

Egurrola, E. (2020). Configuración de la región de estudio (documento interno de trabajo).

Espeitx, E. (2008). Los sentidos del patrimonio alimentario en el Sur de Europa. En F. Xavier Medina y Marcelo Álvarez (eds.), Identidades en el plato. El patrimonio cultural alimentario entre Europa y América (pp. 45-61). Barcelona: Icaria editorial.

Estadística de Producción Agrícola. (2020). recuperado de http://infosiap. siap.gob.mx/gobmx/datosAbiertos.php

Fischler, C., y Solana, J. (2010). Gastrono-nomía y gasto-anomía. Sabiduría del cuerpo y crisis biocultural de la alimentación moderna. Recuperado de http:/ / www.gazeta-antropologia.es/?p=1592 
Fonte, M. (2008). Knowledge, Food and Place. A way of producing, a way of knowing. Sociologia ruralis, 48(3), 200-222.

Fournier, S., y Muchnik, J. (2012). El enfoque "SIAL" (Sistemas Agroalimentarios Localizados) y la activación de recursos territoriales. Agroalimentaria, 18(34), 133-144.

Friedmann, H., y McMichael, P. (1989). Agriculture and the state system: the rise and decline of national agricultures, 1870 to the present. Sociologia Ruralis, 29(2), 93-117.

García, P. (2012). Reconciliando comercio, justicia y medio ambiente. Comercio, nuevas fórmulas para viejos problemas. Ábaco, 3(73), 99-104.

García-Yánez, J., y Emanuel, R. (2020) The Kino heritage Fruit Trees Proyect. Arizona-Sonora Desert Museum, 2020. Recuperado de https://www.desertmuseum.org/center/kinofruittrees.php

Guzmán-Sevilla, E. (2017). Sobre las perspectivas teórico-metodológicas de agroecología. Redes Revista de Desenvolvimiento Regional, 22(2), 13-30.

Hatanaka, M., y Busch, L. (2008). Third-party certification in the global agrifood system: an objective or socially mediated governance mechanism? Sociologia Ruralis, 48(1), 73-91.

Hernández, M., y A. Villaseñor. (2014). La calidad en el sistema agroalimentario globalizado. Revista Mexicana de Sociología, 76(4), 557-82.

Hernández, M. C. , y Ochoa, J. L. (2012). Dinámicas colectivas en una región quesera de Sonora. Análisis desde la perspectiva de los sistemas agroalimentarios localizados. En B. Cavallotti, A. Cesín, B. Ramírez, C. Marcof (coords.), Ganadería y alimentación: alternativas frente a la crisis ambiental y el cambio social (pp. 131-145). Ciudad de México: CONACYT, SAGARPA, UACH, Colegio Posgraduados, UNAM y UAEM.

Instituto Mexicano de Tecnología del Agua. (2020). Precipitaciones Ímuris (Ranchito). Recuperado de https://www.imta.gob.mx/productos/software/ eric-iii-version-3-2-extractor-rapido-de-informacion-climatolo-detail

Instituto Nacional de Estadística y Geografía (INEGI). (2009a). Prontuario de información geográfica municipal de los Estados Unidos Mexicanos, Ímuris, Sonora, Clave Geoestadística 26305. Recuperado de http:/ /www3.inegi.org. $\mathrm{mx} /$ contenidos/app/mexicocifras/datos_geograficos/26/2603.pdf

Instituto Nacional de Estadística y Geografía (INEGI). (2009b). Prontuario de información geográfica municipal de los Estados Unidos Mexicanos, Magdalena, Sonora, Clave Geoestadística 26306. Recuperado de http://www3.inegi. org.mx/contenidos/app/mexicocifras/datos_geograficos/26/2603.pdf

Instituto Nacional de Estadística y Geografía (INEGI). (2017). Anuario estadístico y geográfico de Sonora 2017. México: Instituto Nacional de Estadística y Geografía.

Instituto Nacional de Estadística y Geografía (INEGI). (2018). Encuesta Nacional de Ingresos y Gastos de los Hogares 2018. Recuperado de https://www.inegi. org.mx/contenidos/programas/enigh/nc/2018/doc/enigh2018_ns_ presentacion_resultados.pdf

Instituto Nacional de Estadística y Geografía (INEGI). (2020). México en cifras. Recuperado de https://www.inegi.org.mx/app/areasgeograficas/\#tabMCcollapse-Indicadores 
Kranjac, M., Vapa-Tankosić, J., y Knežević, M. (2017). Profile of Organic Food Consumers. Econonomics of Agriculture, 62(2), 497-514.

León, J., Hernández, M. C., Andablo, A., y Ulloa, A. (2006). Programa Especial Concurrente del Distrito de Desarrollo Rural 140-Magdalena de Kino, Sonora. Hermosillo: CIAD, A.C.-SAGARPA.

Linck, T., Barragán, E., y Casabianca, F. (2006). De la propiedad intelectual a la calificación de los territorios: lo que cuentan los quesos tradicionales. Agroalimentaria (22), 99-109.

Macías, R., Grijalva, R., y Robles, F. (2007). Los suelos agrícolas de la región del río Magdalena y sus propiedades físico-químicas. Biotecnia, 9(2), 29-38.

Matas, A. (2018). Diseño del formato de escalas tipo Likert: un estado de la cuestión. Revista Electrónica de Investigación Educativa, 20(1), 38-47.

McMichael, P. (2009). A food regime genealogy. The Journal of Peasant Studies, 36(1), 139-169.

McMichael, P. (2014). Food Regimes and Agrarian Questions. Agrarian Change \& Peasant Studies (Book 3). Practical Action Publishing y Fernwood Publishing (edición de Kindle).

Mount, P. (2011). Growing local food: scale and local food systems governance. Agriculture and Human Values, 29(1), 107-21.

Muchnik, J. (2006). Sistemas agroalimentarios localizados: evolución del concepto y diversidad de situaciones. III Congreso Internacional de la Red SIAL "Sistemas Agroalimentarios Locales", Alimentación y Territorios (pp. 21). Baeza, España: ALTER.

Nigh, R., y González, A. (2015). Reflexive consumer markets as opportunities for new peasant farmers in Mexico and France: constructing food sovereignty through alternative food networks. Agroecology and Sustainable Food Systems, 39(3), 317-341. doi: 10.1080/21683565.2014.979545

Ortega T., Vásquez, V., Flores, D., y Núñez, J. (2017). Agrobiodiversidad, género y soberanía alimentaria en Tlaxiaco, Oaxaca. Revista Mexicana de Ciencias Agrícolas (18), 3673-3682.

Otero, G. (2013). El régimen alimentario neoliberal y sus crisis: Estado, agroempresas multinacionales y biotecnología. Antípoda. Revista de Antropología y Arqueología, (17), 49-78.

Ransom, E., Bain, C., y Higgins, V. (2013). Private agri-food standards: supply chains and the governance of standards. International Journal of Sociology of Agriculture and Food, 20(2), 147-154.

Rugren. (2017). ¿Cuál es tu generación? -Baby boom, generaciones; X, Y (milenial), Z. Recuperado de https://rugren.es/cual-es-tu-generacion/

Ruiz, R. (2020). Terrenate es una ruta petroglifa. El Imparcial. Recuperado de https: / / www.elimparcial.com/sonora/sonora/Terrenate-es-una-ruta-petroglifa-20150804-0162.html

Secretaría de Agricultura, Ganadería, Desarrollo Rural, Pesca y Alimentación (SAGARPA). (2017). Programa de Apoyos a Pequeños Productores, componente: el campo en nuestras manos; establecimiento de Huertos Frutales (membrillo) 42 hectáreas; pp. 1-41.

Salido, P. (2018). Distribución de visitantes 2018 (documento interno de trabajo), Hermosillo: Centro de Investigación en Alimentación y Desarrollo. 
Salido, P., López, M., Bañuelos, N., Romo, E., Romero, D., y Wong, P. (2009). Plan rector de desarrollo turístico sustentable para la ruta de las Misiones. Hermosillo: Centro de Investigación en Alimentación y Desarrollo y Comisión de Fomento al Turismo del estado de Sonora.

Sánchez, M. (2010). Presentación. En C. Maya y M. Hernández (coords.), Globalización y sistemas agroalimentario (pp. 11-14). Culiacán: Universidad Autónoma de Sinaloa, Centro de Investigación en Alimentación y Desarrollo, Asociación Mexicana de Estudios Rurales y Juan Pablos Editor.

Secretaría de Turismo (SECTUR). (2014). Magdalena de Kino, Sonora. Recuperado de http://www.sectur.gob.mx/gobmx/pueblos-magicos/magdalena-de-kino-sonora/

Törey, S. (2010). El valioso toque competitivo que otorga el "alma de la gente”. Equitierra, Revista Rural Latinoamericana (5), 14-20.

Turner, K., y Davidson-Hunt, L. (2016). Tensions and synergies in the Central Valley of Tarija, Bolivia: commercial viticulture and agrobiodiversity in sma-

llholder farming systems. Agroecology and Sustainable Food Systems, 40(6), 518-552. doi: 10.1080/21683565.2016.1151473

Ulloa, M. (2020). Municipios productores de membrillo 1950, 1960 y 1970. (Documento interno de trabajo). Laboratorio de Innovación Rural. Hermosillo: Centro de Investigación en Alimentación y Desarrollo.

Vandecandelaere, E., Arfini, F., Belletti, G., y Marescotti, A. (2010). Uniendo personas, territorios y productos: guía para fomentar la calidad vinculada al origen y las indicaciones geográficas sostenibles. Recuperado de http:// www.fao.org/3/a-i1760s.pdf

Verain, M., Bartels, J., Dagevos, H., Sijtsema, S., Onwezen, M., y Antonides, G. (2012). Segments of sustainable food consumers: a literature review. International Journal of Consumer Studies, 36, 123-132.

Vessia, F. (2019). Towards Consumer Social Responsibility. Journal of Economics and Management, 38(4), 157-181.

Viertel, J. (2013). Más allá que "votas con el tenedor": de la conciencia alimentaria a la construcción de movimientos. En Eric Holt-Giménez (ed.), ¡Movimientos alimentarios uníos! Estrategias para transformar nuestros sistemas alimentarios (pp. 155-207). Bogotá: Instituto Latinoamericano para una Sociedad y un Derecho Alternativos e Institute for Food and Development Policy.

Villegas, A., y Cervantes, F. (2011). La genuinidad y tipicidad en la revalorización de los quesos artesanales mexicanos. Estudios sociales, 19(38), 145164. 